American Journal of Applied Sciences 5 (7): 835-843, 2008

ISSN 1546-9239

(C) 2008 Science Publications

\title{
A Multi-Objective HPSO Algorithm Approach for Optimally Location of UPFC in Deregulated Power Systems
}

\author{
Seyed Abbas Taher and Seyed Mohammad Hadi Tabei \\ Department of Electrical Engineering, University of Kashan, Kashan, Iran
}

\begin{abstract}
This paper presents the application of hybrid particle swarm optimization technique to find optimal location of unified power flow controller to achieve optimal power flow. Objective function in the OPF, that is to be minimized, are the overall cost functions, which include the total active and reactive production cost function of the generators and installation cost of UPFCs. The OPF constraints are generators, transmission lines and UPFCs limits. We propose HPSO algorithm to consider the objective function and all equality and inequality constraints. Simulations are performed on 4 bus test system and modified IEEE 14 bus system for optimal location of UPFC and the results obtained are encouraging and will be useful in electrical restructuring.
\end{abstract}

Keywords: Deregulated Power System, Hybrid Particle Swarm Optimization, Optimal Location, Optimal Power Flow, Unified Power Flow Controller

\section{INTRODUCTION}

Nowadays, actual power systems are facing new challenges due to deregulation and restructuring of the electricity markets. Hence, in order to be able to obtain a high operational efficiency and networks security, large interconnected systems have been built. In this context, one possible solution to improve the system operation was the use of FACTS technologies ${ }^{[1]}$.

OPF is a very large, non-linear mathematical programming problem. The main purpose of OPF is to determine the optimal operation state of a power system while meeting some specified constraints. Since the OPF solution was introduced by Squires ${ }^{[2]}$, considerable amount of research on different optimization algorithms and solution methods have been done. Among the solution methods for OPF problem, Newton's method is the most commonly applied. Newton's method requires the creation of the Lagrangian function combined of objective function with equality and inequality constraints functions by best Lagrangian multipliers. OPF solution is the optimum point of Lagrangian function in which the gradient of Lagrangian function with respect to the state variables and Lagrange multipliers must be equal to zero. Accordingly this method requires the initial guess of the state variables, initial guess of the Lagrange multipliers and calculate the gradient and Hessian (second partial derivatives matrix) of the Lagrangian. However, problems arise with the considerations of FACTS devices in OPF. The controllable parameters of UPFC cannot be added directly to those existing OPF techniques because these parameters will change the admittance matrix.

Population based, cooperative and competitive stochastic search algorithms had been very popular in the recent years in the research area of computational intelligence. Some well established search algorithms such as genetic algorithm $(\mathrm{GA})^{[3]}$ and evolutionary programming (EP) ${ }^{[4,5]}$ are successfully implemented to solve simple and complex problems efficiently and effectively. Most of the population based search approaches are motivated by evolution as seen in nature. Particle swarm optimization (PSO), on the other hand, is motivated from the simulation of social behavior. The PSO algorithm was first introduced by Eberhart and Kennedy ${ }^{[6,7]}$. Instead of using evolutionary operators to manipulate the individuals (called particles), similar to other evolutionary computational algorithms, each particle in PSO flies in the search space with a velocity which is dynamically adjusted according to particle and its companion flying experiences. Unlike in genetic algorithms, evolutionary programming, and evolution strategies, in PSO, the selection operation is not performed. All particles in PSO are kept as members of the population through the course of the run (a run is defined as the total number of generations of the evolutionary algorithms prior to termination). It is the velocity of the particle which is

Corresponding Author: Seyed Abbas Taher, Department of Electrical Engineering, University of Kashan, Kashan, Iran, Tel: +98-9131614352 
updated according to its own previous best position and the previous best position of its companions. The particles fly with the updated velocities. PSO is the only evolutionary algorithm that does not implement survival of the fittest. PSO is now applied for solving electrical engineering related problems ${ }^{[8]}$. Hybrid PSO algorithms are other research trends to merge or combine the PSO with the other techniques, especially the other evolutionary computation techniques ${ }^{[9,10]}$.

Many researches were made on the optimal location of FACTS devices using different techniques such as GA, hybrid tabu approach, simulated annealing (SA) and PSO. The best location for a set of phase shifters was found by GA to reduce the flows in heavily loaded lines resulting in an increased loadability of the network and reduced cost of production ${ }^{[11]}$. The best optimal location of FACTS devices in order to reduce the production cost along with the device's cost using real power flow performance index was reported ${ }^{[12]}$. A hybrid tabu search and simulated annealing was proposed to minimize the generator fuel cost in OPF control with multi-type FACTS devices ${ }^{[13]}$. Optimal location of FACTS devices was found using PSO technique for considering system loadability and cost of installation $^{[14]}$.

This paper proposes an application of HPSO to solve the optimal location of UPFC problems in restructured power systems for considering system loadability and the overall cost function, which includes the generation costs of power plants and the cost of UPFC installation. Therefore, the presented problem becomes a multi-objective optimization problem. location and rated value of UPFC must be determined simultaneously.

\section{MATERIALS AND METHODS}

The UPFC is a FACTS device which is capable of providing active and reactive load flow control between its terminals. It may also provide reactive power compensation to the node at which it is connected ${ }^{[15,16]}$. The device consists of two converters connected together by a common DC link as shown in Fig. 1.

These converters are connected to the power system via coupling transformers. One converter is connected in shunt to the sending end node while the second converter is connected in series between the sending and receiving end nodes. The UPFC can not generate or absorb active power and as such the active power in the

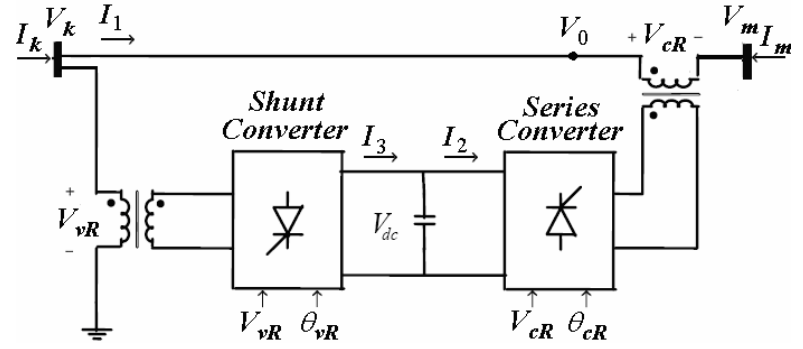

Fig. 1: UPFC installed in power system

two converters must balance when active power loss is neglected. This is achieved via the DC link. The converters, however, may generate or absorb reactive power.

The UPFC equivalent circuit shown in Fig. 2 is used to derive the steady-state model ${ }^{[17]}$.

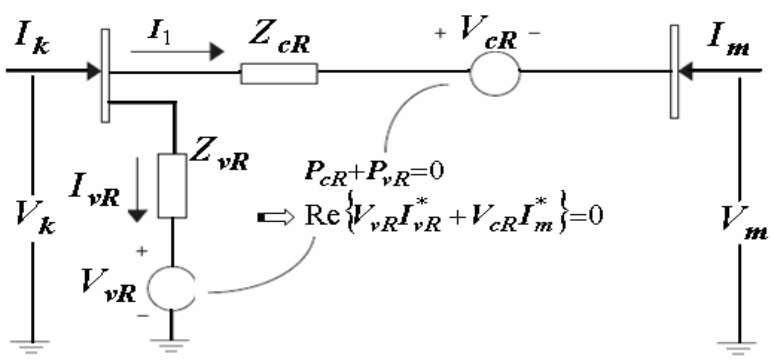

Fig. 2: UPFC equivalent circuit

The equivalent circuit consists of two ideal voltage sources representing the fundamental Fourier series component of the switched voltage waveforms at the AC converter terminals. The UPFC voltage sources are:

$V_{v R}=\left|V_{v R}\right|\left(\cos \theta_{v R}+j \sin \theta_{v R}\right)$
$V_{c R}=\left|V_{c R}\right|\left(\cos \theta_{c R}+j \sin \theta_{c R}\right)$

Where $V_{v R}$ and $\theta_{v R}$ are the controllable magnitude $\left(V_{v R \text { min }} \leq V_{v R} \leq V_{v R \text { max }}\right) \quad$ and $\left(0 \leq \theta_{v R} \leq 2 \pi\right)$ phase angle of the voltage source representing the shunt converter. The magnitude $V_{c R}$ and phase angle $\theta_{c R}$ of the voltage source representing the series converter are controlled between limits: $\left(V_{c R \text { min }} \leq V_{c R} \leq V_{c R \text { max }}\right)$, $\left(0 \leq \theta_{c R} \leq 2 \pi\right)$.

A. Power flow calculation with UPFC devices: This section explains the power flow calculation with UPFC 
devices ${ }^{[17]}$. Based on the equivalent circuit shown in Fig. 2, the active and reactive power equations are: At bus k:

$$
\begin{gathered}
P_{k}=V_{k}^{2} G_{k k}+V_{k} V_{m}\left(G_{k m} \cos \left(\theta_{k}-\theta_{m}\right)\right. \\
\left.+B_{k m} \sin \left(\theta_{k}-\theta_{m}\right)\right) \\
+V_{k} V_{c R}\left(G_{k m} \cos \left(\theta_{k}-\theta_{c R}\right)\right. \\
\left.+B_{k m} \sin \left(\theta_{k}-\theta_{c R}\right)\right) \\
+V_{k} V_{v R}\left(G_{v R} \cos \left(\theta_{k}-\theta_{v R}\right)\right. \\
\left.+B_{v R} \sin \left(\theta_{k}-\theta_{v R}\right)\right) \\
Q_{k}=-V_{k}^{2} B_{k k}+V_{k} V_{m}\left(G_{k m} \sin \left(\theta_{k}-\theta_{m}\right)\right. \\
\left.-B_{k m} \cos \left(\theta_{k}-\theta_{m}\right)\right) \\
+V_{k} V_{c R}\left(G_{k m} \sin \left(\theta_{k}-\theta_{c R}\right)\right. \\
\left.-B_{k m} \cos \left(\theta_{k}-\theta_{c R}\right)\right) \\
+V_{k} V_{v R}\left(G_{v R} \sin \left(\theta_{k}-\theta_{v R}\right)\right. \\
\left.-B_{v R} \cos \left(\theta_{k}-\theta_{v R}\right)\right)
\end{gathered}
$$

At bus m:

$$
\begin{array}{r}
P_{m}=V_{m}^{2} G_{m m}+V_{m} V_{k}\left(G_{m k} \cos \left(\theta_{m}-\theta_{k}\right)\right. \\
\left.+B_{m k} \sin \left(\theta_{m}-\theta_{k}\right)\right) \\
+V_{m} V_{c R}\left(G_{m m} \cos \left(\theta_{m}-\theta_{c R}\right)\right. \\
\left.+B_{m m} \sin \left(\theta_{m}-\theta_{c R}\right)\right) \\
Q_{m}=-V_{m}^{2} B_{m m}+V_{m} V_{k}\left(G_{m k} \sin \left(\theta_{m}-\theta_{k}\right)\right. \\
\left.-B_{m k} \cos \left(\theta_{m}-\theta_{k}\right)\right) \\
+V_{m} V_{c R}\left(G_{m m} \sin \left(\theta_{m}-\theta_{c R}\right)\right. \\
\left.-B_{m m} \cos \left(\theta_{m}-\theta_{c R}\right)\right)
\end{array}
$$

Series converter:

$$
\begin{gathered}
P_{c R}=V_{c R}^{2} G_{m m}+V_{c R} V_{k}\left(G_{k m} \cos \left(\theta_{c R}-\theta_{k}\right)\right. \\
\left.+B_{k m} \sin \left(\theta_{c R}-\theta_{k}\right)\right) \\
+V_{c R} V_{m}\left(G_{m m} \cos \left(\theta_{c R}-\theta_{m}\right)\right. \\
\left.+B_{m m} \sin \left(\theta_{c R}-\theta_{m}\right)\right) \\
Q_{c R}=-V_{c R}^{2} G_{m m}+V_{c R} V_{k}\left(G_{k m} \sin \left(\theta_{c R}-\theta_{k}\right)\right. \\
\left.-B_{k m} \cos \left(\theta_{c R}-\theta_{k}\right)\right) \\
+V_{c R} V_{m}\left(G_{m m} \sin \left(\theta_{c R}-\theta_{m}\right)\right. \\
\left.-B_{m m} \cos \left(\theta_{c R}-\theta_{m}\right)\right)
\end{gathered}
$$

Shunt converter:

$$
\begin{gathered}
P_{v R}=-V_{v R}^{2} G_{v R}+V_{v R} V_{k}\left(G_{v R} \cos \left(\theta_{v R}-\theta_{k}\right)\right. \\
\left.+B_{v R} \sin \left(\theta_{v R}-\theta_{k}\right)\right) \\
Q_{v R}=V_{v R}^{2} B_{v R}+V_{v R} V_{k}\left(G_{v R} \sin \left(\theta_{v R}-\theta_{k}\right)\right. \\
\left.-B_{v R} \cos \left(\theta_{v R}-\theta_{k}\right)\right)
\end{gathered}
$$

Where

$Y_{k k}=G_{k k}+j B_{k k}=Z_{c R}^{-1}+Z_{v R}^{-1}$

$Y_{m m}=G_{m m}+j B_{m m}=Z_{c R}^{-1}$

$Y_{k m}=Y_{m k}=G_{k m}+j B_{k m}=-Z_{c R}^{-1}$

$Y_{v R}=G_{v R}+j B_{v R}=-Z_{v R}^{-1}$

And assuming loss-less converter: $P_{v R}+P_{c R}=0$.

The UPFC linearised power equations are combined with the linearised system of equations corresponding to the rest of the network,

$[f(x)]=[J][\Delta X]$

Where

$[f(x)]=\left[\begin{array}{lllllll}\Delta P_{k} & \Delta P_{m} & \Delta Q_{k} & \Delta Q_{m} & \Delta P_{m k} & \Delta Q_{m k} & \Delta P_{b b}\end{array}\right]^{T}$

$\Delta P_{b b}$ is the power mismatch and the superscript $\mathrm{T}$ indicates transposition. $\Delta X$ is the solution vector and $J$ is the Jacobian matrix. The power mismatch equations are used as the guiding principle for conducting limit revisions ${ }^{[7]}$. The mismatch provides an accurate indicator for determining the activation of limits revision for the controllable devices parameters.

The revision criterion of the UPFC is based on its active power converter mismatch equation.

\section{B. PSO and HPSO algorithm definition}

The PSO definition is presented as follows ${ }^{[6,7]}$.

1) Each individual particle $i$ has the following properties:

$x_{i}:$ a current position in search space

$v_{i}:$ a current velocity in search space

$y_{i}$ : a personal best position in search space

2) The personal best position $p_{i}$ corresponds to the position in search space, where particle $i$ presents the smallest error as determined by the objective function $f$, assuming a minimization task.

3) The global best position denoted by $g$ represents the position yielding the lowest error among all the $p_{i}$ 's. 
Equations (13) and (14) define how the personal and global best values are updated at time $\mathrm{k}$, respectively. In below, it is assumed that the swarm consists of $\mathrm{s}$ particles.

Thus, $i \in 1, \ldots, s$

$$
\begin{aligned}
& p_{i}^{k+1}= \begin{cases}p_{i}^{k} & \text { if } f\left(p_{i}^{k}\right) \leq f\left(X_{i}^{k+1}\right) \\
X_{i}^{k+1} & \text { if } f\left(p_{i}^{k}\right)>f\left(X_{i}^{k+1}\right)\end{cases} \\
& g^{k} \in\left\{p_{1}^{k}, p_{2}^{k}, \ldots, p_{s}^{k}\right\} \mid f\left(g^{k}\right)= \\
& \min \quad\left\{f\left(p_{1}^{k}\right), f\left(p_{2}^{k}\right) \ldots f\left(p_{s}^{k}\right)\right\}
\end{aligned}
$$

During each iteration, every particle in the swarm is updated using (15) and (16). Two pseudorandom sequences $r_{1} \sim U(0,1)$ and $r_{2} \sim U(0,1)$ are used to affect the stochastic nature of the algorithm.

$$
\begin{aligned}
& v_{i}^{k+1}=w \times v_{i}^{k}+c_{1} \times \operatorname{rand}()_{1} \times\left(p_{i}^{k}-X_{i}^{k}\right) \\
& +c_{2} \times \operatorname{rand}()_{2} \times\left(g^{k}-X_{i}^{k}\right) \\
& X_{i}^{k+1}=X_{i}^{k}+v_{i}^{k+1} \\
& w=w_{\max }-\frac{w \max -w \min }{\text { iter } \max } \times \text { iter } \\
& v_{\max }=k \times x_{\max } \quad 0.1 \leq k \leq 1
\end{aligned}
$$

Where

$v_{i}^{k}$ :velocity of $\mathrm{i}^{\text {th }}$ particle at $\mathrm{k}^{\text {th }}$ iteration,

$v_{i}^{k+1}:$ velocity of $\mathrm{i}^{\text {th }}$ particle at $(\mathrm{k}+1)^{\text {th }}$ iteration,

$w$ : inertia weight,

$X_{i}^{k}$ : position of $\mathrm{i}^{\text {th }}$ particle at $\mathrm{k}^{\text {th }}$ iteration,

$X_{i}^{k+1}$ : position of $\mathrm{i}^{\text {th }}$ particle at $(\mathrm{k}+1)^{\text {th }}$ iteration,

$c_{1}, c_{2}$ : positive constants both equal to 2 ,

iter, iter $_{\max }$ : iteration number and maximum iteration number,

and $\operatorname{rand}()_{1}, \operatorname{rand}()_{2}:$ random number selected between 0 and 1 .

Evolutionary operators like selection, crossover and mutation have been applied into the PSO. By applying selection operation in PSO, the particles with the best performance are copied into the next generation, therefore, PSO can always keep the best performed particles ${ }^{[9]}$. By applying crossover operation, information can be exchanged or swapped between two particles so that they can "fly" to the new search area as in evolutionary programming and genetic algorithms ${ }^{[10]}$. Among the three evolutionary operators, the mutation operators are the most commonly applied evolutionary operators in PSO. The purpose of applying mutation to PSO is to increase the diversity of the population and the ability to have the PSO to escape the local $\operatorname{minima}^{[18-21]}$.

\section{OPTIMAL LOCATION OF UPFC}

A. Optimization by penalty factor: Constrained optimization is one of the most common application areas for PSO. One of the major issues for solving constrained optimization problems is how to handle the constraints. A straight forward approach is to convert the constrained optimization problem into a nonconstrained optimization problem by adding penalty for violation of constraints ${ }^{[22]}$.

Optimal placement of UPFC considering objective function, system loadability and voltage stability has been mathematically formulated and is given by the following equation:

$\operatorname{Min} L(X)=f(X)+P F \times\|J-1\|$
$J=\prod_{\text {Line }} O V L_{\text {Line }} \times \prod_{\text {Bus }} V S_{\text {Bus }}$

Where, $f(x)$ objective function, PF is penalty factor, value ranges from $10^{30}$ to $10^{35}$, OVL is line overload factor for a line and VS is voltage stability index for a bus. The cost is optimized with the following constraints:

$O V L= \begin{cases}1 & \text { if } S_{p q} \leq S_{p q}^{\max } \\ \exp \left(\lambda\left|1-\frac{S_{p q}}{S_{p q}^{\max }}\right|\right) & \text { if } \quad S_{p q}>S_{p q}^{\max }\end{cases}$
$V S= \begin{cases}1 & \text { if } 0.9 \leq V_{b} \leq 1.1 \\ \exp \left(\mu\left|1-V_{b}\right|\right) & \text { otherwise }\end{cases}$

Where, $S_{p q}$ is complex power flow between buses $\mathrm{p}$ and $\mathrm{q}, \mathrm{S}_{p q}$ is thermal limit for the line between buses $\mathrm{p}$ and $\mathrm{q}, V_{\mathrm{b}}$ is voltage at bus $\mathrm{b}$ and $\lambda, \mu$ are small positive constants both equal to 0.1 . 
B. Objective function: Optimal placement of UPFC is multi-objective optimization (MOO) problem. Objective functions are the generation costs of power plants and installation cost of UPFC.

$$
f(X)=\sum_{i=1}^{N G} C_{g p_{i}}\left(P_{g_{i}}\right)+C_{g q_{i}}\left(Q_{g_{i}}\right)+\sum_{j=1}^{N} C_{U P F C_{j}}^{t}
$$

Where

$$
C_{g p_{i}}\left(P_{g_{i}}\right)=a_{i}+b_{i}\left(P_{g_{i}}\right)+c_{i}\left(P_{g_{i}}\right)^{2}
$$

$C_{U P F C_{j}}^{t}=\left(C_{U P F C_{j}} \times S_{j} \times 1000 \times \alpha\right) / 8760$

$C_{U P F C_{j}}=0.0003 S_{j}^{2}-0.2691 S_{j}+188.22$

$\alpha=\frac{r(1+r)^{n}}{(1+r)^{n}-1}$

$C_{g p_{i}}\left(P_{g_{i}}\right)$ : cost of active power production in $\$ h^{-1}$,

$C_{g q_{i}}\left(Q_{g_{i}}\right)$ : cost of reactive power production in $\$ h^{-1}$,

$S_{j}$ : operating range of the FACTS devices in MVAR,

$C_{U P F C_{j}}^{t}$ : cost of installation of UPFC in $\$ h^{-1}$,

$C_{U P F C_{j}}$ : cost of installation of UPFC in \$/KVAR,

$\alpha$ : the capital recovery factor (CRF),

$r$ : the interest rate,

$n$ : the capital recovery plan.

Considering the interest rate $\mathrm{r}=0.05$, the capital recovery period $n=10$ years, the capital recovery factor can be computed, i.e., $\alpha=0.1295$.

Capability curve of a generator is usually used to demonstrate relation between its active and reactive power outputs. A typical capability curve of a generator is shown in Fig. 3. From this figure it can be observed that the active power generation decreases the reactive power capability of generator. The cost of reactive power production can be modeled using opportunity cost calculation ${ }^{[23]}$. An approximation for cost of reactive power production is given in the equation (28).

$$
C_{g q}\left(Q_{g_{i}}\right)=\left[C_{g p_{i}}\left(S_{g_{i, \max }}\right)-C_{g p_{i}}\left(\sqrt{S_{g_{i, \max }^{2}}^{2}-Q_{g_{i}}^{2}}\right)\right] \cdot K
$$

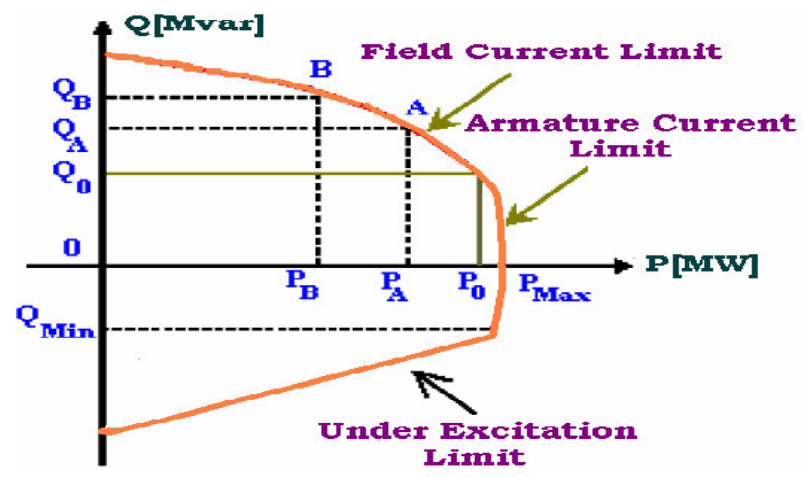

Fig. 3: Capability curve of a generator

Where

$S_{g_{i, \max }}$ : operating range of the generator in bus i.

$K$ : benefit factor of reactive power production selected between 0.05 and 0.1 .

C. Particle representation: HPSO require the parameters of the optimization problem. Since the goal of optimization was to allocate the UPFCs, taking variables control to select this parameters. A particle is represented with the following strings of variables control:

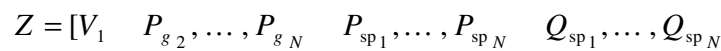

$$
\begin{aligned}
& V_{\text {vrar } 1}, \ldots, V_{\text {vrar } N} \quad U_{P F C n l}, \ldots, U P F C n l_{N} \\
& \text { UPFCside } \left._{1}, \ldots, \text { UPFCside }_{N}\right]
\end{aligned}
$$

Where

$V_{1}$ : is the voltage magnitude of main bus,

$P_{g i}$ : is the active power generations at bus $i$,

$P_{s p i}, Q_{s p i}:$ are the active and reactive powers leaving of $U P F C i$ respectively,

Vvrtar $_{i}$ : target nodal voltage magnitude to be controlled by shunt branch of UPFC $i$,

$U P F C n l_{i}$ : number of compensated transmission line with $U P F C i$,

UPFCside $_{i}$ : status of install UPFC : 1 is status that UPFC installed in sending end of transmission line, 2 is status that UPFC installed in receiving end of transmission line,

$\mathrm{N}$ : is number of UPFC's.

A population of particles is initialized with random positions and velocities in the problem space. 
Am. J. Applied Sci., 5 (7): 835-843, 2008

\section{RESULTS AND DISCUSSION}

The effectiveness of proposed approach is illustrated using 4-bus test system and IEEE 14-bus system. System data and results are based on a 100 MVA and bus 1 is the reference bus. In order to verify the presented models and illustrate the impacts of UPFC we study three cases for test systems.

Case 1: results of OPF without UPFC, with line limits ignored.

Case 2: results of OPF without UPFC.

Case 3: results of optimal location of one UPFC.

A. Four-bus test system: Fig. 4 represents a four-bus test system that, applied to an optimal power flow with DC load flow model ${ }^{[24]}$. We also use the only total active generation cost as the objective function for this test system to find optimal location of UPFC. Generator data are given in Table 1.

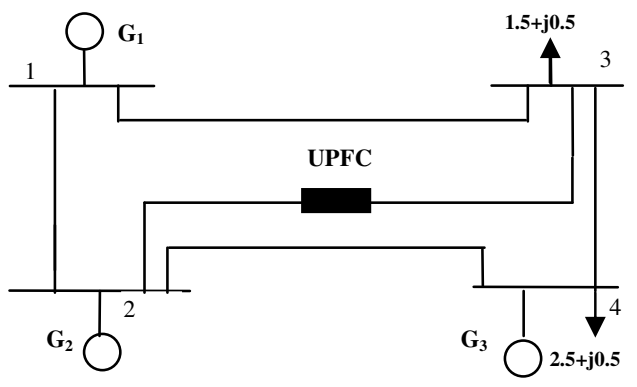

Fig. 4: Four-bus test system

Table 1: Generator data of the four bus test system

\begin{tabular}{cccccccc}
\hline $\mathrm{G}_{\mathrm{i}}$ & $\mathrm{a}_{\mathrm{i}}$ & $\mathrm{b}_{\mathrm{i}}$ & $\mathrm{c}_{\mathrm{i}}$ & $P_{g_{i}}^{\min }$ & $P_{g_{i}}^{\max }$ & $Q_{g_{i}}^{\min }$ & $Q_{g_{i}}^{\max }$ \\
& & & & $(\mathrm{Pu})$ & $(\mathrm{Pu})$ & $(\mathrm{Pu})$ & $(\mathrm{Pu})$ \\
$\mathrm{G}_{1}$ & 230 & 110 & 0.007 & 0.5 & 4 & -1.2 & 1.2 \\
$\mathrm{G}_{2}$ & 200 & 10 & 0.005 & 0.5 & 3.5 & -1.2 & 1.2 \\
$\mathrm{G}_{3}$ & 240 & 12 & 0.009 & 0.5 & 3.5 & -1.2 & 1.2 \\
\hline
\end{tabular}

The data for the UPFC are: $\boldsymbol{X}_{\boldsymbol{c} \boldsymbol{R}}=0.1, \boldsymbol{X}_{\boldsymbol{v} \boldsymbol{R}}=10$, $0 \leq V_{c R} \leq 0.1,0 \leq V_{v R} \leq 1.1,0 \leq \theta_{c R} \leq 2 \pi, 0 \leq \theta_{v \boldsymbol{R}} \leq 2 \pi$.

The results of this test system, for the three cases, are shown in Tables 2, 3 and 4.

As can be observed from Table 2 and 3, when line limits are relaxed, the results of case 1 are the results of the traditional economic dispatch which show a total generation cost of $5381.3 \$ / \mathrm{h}$. For this case, line 2-3 would carry more than its limit, the most expensive generator $\mathrm{G}_{3}$ produces its near minimum limit, and most of the load is served by $G_{2}$ without utilizing UPFC, when line limits are considered (see results of
Table 2: Results of the 4-bus test system

\begin{tabular}{|c|c|c|c|c|}
\hline \multicolumn{2}{|c|}{ Variable } & Case 1 & Case 2 & Case 3 \\
\hline \multicolumn{2}{|c|}{ Total Cost $(\$ / \mathrm{h})$} & 5381.3 & 5440.4 & 5377.9 \\
\hline \multicolumn{2}{|c|}{$P_{g 1}$} & 0.9713 & 1.3102 & 0.9803 \\
\hline \multicolumn{2}{|c|}{$\mathrm{Q}_{\mathrm{g} 1}$} & 0.2914 & 0.6826 & 0.3826 \\
\hline \multicolumn{2}{|c|}{$\mathrm{P}_{\mathrm{g} 2}$} & 2.4439 & 1.6812 & 2.3747 \\
\hline \multicolumn{2}{|c|}{$\mathrm{Q}_{\mathrm{g} 2}$} & 0.1772 & -0.2050 & 0.6942 \\
\hline \multicolumn{2}{|c|}{$\mathrm{P}_{\mathrm{g} 3}$} & 0.6623 & 1.0696 & 0.7162 \\
\hline \multicolumn{2}{|c|}{$Q_{g 3}$} & 0.9696 & 0.7856 & 0.4574 \\
\hline \multicolumn{2}{|c|}{$\mathrm{P}_{\mathrm{gT}}$} & 4.0775 & 4.061 & 4.0712 \\
\hline \multirow{2}{*}{ UPFC } & Send & ------- & ------- & 0.9548 \\
\hline & Rec. & ------- & ------- & -0.9548 \\
\hline \multirow{3}{*}{ UPFC } & Send & ------- & ------- & 0.4882 \\
\hline & Rec. & ------- & ------- & -0.2971 \\
\hline & & 0.0775 & 0.0610 & 0.0712 \\
\hline
\end{tabular}

Table 3: Results of complex power line 4-bus system

\begin{tabular}{|c|c|c|c|c|c|}
\hline \multirow{2}{*}{ Line } & & \multicolumn{3}{|c|}{$\begin{array}{l}\text { Complex Power } \\
\text { (S) }\end{array}$} & \multirow[t]{3}{*}{$\begin{array}{l}\text { Line } \\
\text { Limits }\end{array}$} \\
\hline & & Case & Case & Case & \\
\hline & & 1 & 2 & 3 & \\
\hline \multirow{2}{*}{ Line $_{12}$} & Send & 0.18 & 0.48 & 0.07 & \multirow{2}{*}{0.7} \\
\hline & Rec. & 0.22 & 0.5 & 0.15 & \\
\hline \multirow{2}{*}{ Line $_{13}$} & Send & 0.83 & 1 & 1 & \multirow[b]{2}{*}{1} \\
\hline & Rec. & 0.8 & 0.95 & 0.96 & \\
\hline \multirow{2}{*}{ Line $_{23}$} & Send & 1.26 & 1 & 1 & \multirow{2}{*}{1} \\
\hline & Rec. & 1.22 & 0.98 & 0.98 & \\
\hline \multirow{2}{*}{ Line $_{24}$} & Send & 1.39 & 1.08 & 1.5 & \multirow{2}{*}{1.5} \\
\hline & Rec. & 1.39 & 1.07 & 1.42 & \\
\hline \multirow[b]{2}{*}{ Line $_{34}$} & Send & 0.51 & 0.39 & 0.37 & \multirow{2}{*}{0.7} \\
\hline & Rec. & 0.51 & 0.39 & 0.37 & \\
\hline
\end{tabular}

Table 4: Parameters of UPFC in 4-bus system

\begin{tabular}{ccccc}
\hline $\begin{array}{c}\text { Control } \\
\text { parameters of } \\
\text { UPFC }\end{array}$ & \multicolumn{2}{c}{ Series source } & \multicolumn{2}{c}{ Shunt source } \\
$\mathrm{V}_{\mathrm{cR}}$ & $\theta_{c R}$ & $\begin{array}{c}\mathrm{V}_{\mathrm{vR}} \\
(\mathrm{pu})\end{array}$ & $\begin{array}{c}\theta_{v R} \\
(\mathrm{deg})\end{array}$ & $(\mathrm{pu})$ \\
\hline HPSO & 0.0185 & -138.8 & 0.0780 & -105.3 \\
\hline
\end{tabular}

case 2), two of the lines (Lines 1-3 and 2-3) carry their maximum thermal limits, which present congestion condition. This condition will prevent loads to be served from generators as obtained from the cheapest combination of generator outputs as in case 1 . Note that the most expensive generator $\mathrm{G}_{4}$ which was producing 66.23 MW in case 1 is now producing 106.96 MW and a cheaper generator $\mathrm{G}_{2}$ is dispatched back. This dispatch of generators contributes an increase to the total production cost of generators (increased from $5381.3 \$ / \mathrm{h}$ to $5440.4 \$ / \mathrm{h}$ ). However, when UPFC is placed between buses 2 and 3 near bus 1, a cheaper dispatch is obtained (see results of case3) where the total cost has been reduced by $62.5 \$ / \mathrm{h}$. As another 
remark, the generators are now producing output very close to the outputs obtained in the merit-order (compare results of case 3 to results of case1). The control parameters of UPFC in 4-bus system is shown in Table 4.

B. IEEE-14 bus test system: In this section, the modified IEEE-14 bus system, as shown in Fig. 5, has been used to test the effectiveness of the proposed method. The test system data can be found in ${ }^{[25]}$. For evaluation of proposed method, load in this system assumed is increased to $75 \%$. We use the total active and reactive production cost function of the generators and cost of installation of UPFC as the objective function for this test system to find optimal location of UPFC. Generator data are given in Table 5. The data for the UPFC are :

$X_{c R}=0.1, X_{v R}=0.1,0.001 \leq V_{c R} \leq 0.2,0.9 \leq V_{v R} \leq 1.1$,

$0 \leq \theta_{c R} \leq 2 \pi, 0 \leq \theta_{\nu R} \leq 2 \pi$.

Table 5: Generator data of the IEEE-14 bus test system

\begin{tabular}{ccccccccc}
\hline $\mathrm{G}_{\mathrm{i}}$ & $\begin{array}{c}\text { No. } \\
\text { Bus }\end{array}$ & $\mathrm{a}_{\mathrm{i}}$ & $\mathrm{b}_{\mathrm{i}}$ & $\mathrm{c}_{\mathrm{i}}$ & $\begin{array}{c}P_{g_{i}}^{\min } \\
(\mathrm{pu})\end{array}$ & $\begin{array}{c}P_{g_{i}}^{\max } \\
(\mathrm{pu})\end{array}$ & $\begin{array}{c}Q_{g_{i}}^{\min } \\
(\mathrm{pu})\end{array}$ & $\begin{array}{c}Q_{g_{i}}^{\max } \\
(\mathrm{pu})\end{array}$ \\
\hline $\mathrm{G}_{1}$ & 1 & 100 & 15 & 0.02 & 0.3 & 2 & -0.5 & 0.5 \\
$\mathrm{G}_{2}$ & 2 & 100 & 10 & 0.01 & 0.2 & 2.7 & -0.8 & 1 \\
$\mathrm{G}_{3}$ & 3 & 100 & 30 & 0.05 & 0.2 & 2 & -0.8 & 0.8 \\
$\mathrm{G}_{4}$ & 6 & 100 & 20 & 0.03 & 0.4 & 2 & -0.7 & 0.7 \\
$\mathrm{G}_{5}$ & 8 & 100 & 30 & 0.05 & 0.2 & 2.5 & -0.8 & 0.8 \\
\hline
\end{tabular}

There are three cases to be discussed. The results are shown in Tables 6, 7 and 8. As can be observed from Table 6 and 7, when line limits are relaxed, the results of case 1 are the results of the traditional economic dispatch which show a total active and reactive power generation cost of $8972.2 \$ / \mathrm{h}$. For this case, lines 2-5 and 4-5 would carry more than their limits, the most expensive generators $G_{3}$ and $G_{5}$ produces their minimum limits and near minimum limit respectively.

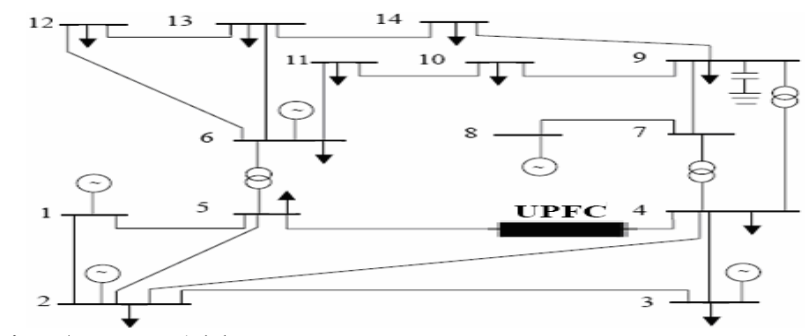

Fig. 5: IEEE-14 bus test system

This condition will prevent loads to be served from generators as obtained from the cheapest combination of generator outputs as in case 1 . Note that the most expensive generator $\mathrm{G}_{5}$ which was producing $20 \mathrm{MW}$ in case 1 is now producing $95.1 \mathrm{MW}$ and a cheaper generator $G_{2}$ is dispatched back. This dispatch of generators contributes an increase to the total active and reactive power production cost of generators (increased from $8972.2 \$ / \mathrm{h}$ to $10337 \$ / \mathrm{h})$.

Table 6: Results of the IEEE- 14 bus test system

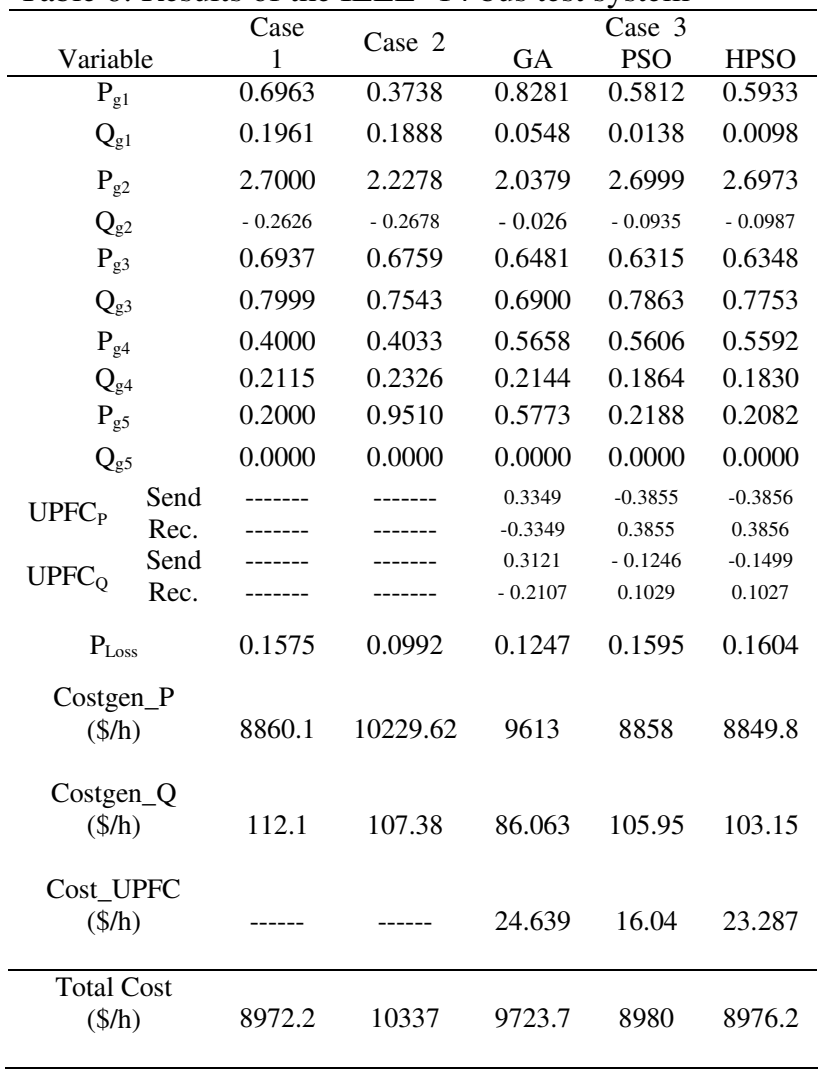

Case 3 contains the results of UPFC optimal location with three evolutionary algorithms, GA, PSO and HPSO in the same iteration. In the all algorithms UPFC is allocated between buses 4 and 5, but in the GA technique near bus 5 and in the other algorithms near bus 4. However, a cheaper dispatch is obtained with HPSO algorithm (see results of case3) where the total cost (the total active and reactive power production cost of generators and installation cost of UPFC) has been reduced by $1360.8 \$ / \mathrm{h}$. In the GA and PSO techniques the total cost has been reduced by 613.3 and $1357 \$ / \mathrm{h}$ respectively. As another remark, the generators in HPSO technique are now producing output very close to the outputs obtained in the merit-order (compare results of case 3 to results of case 1 ). The control parameters of UPFC in IEEE 14-bus is shown in Table 8. 
Table 7: Results of complex power line in IEEE-14 bus system

\begin{tabular}{|c|c|c|c|c|c|c|c|}
\hline \multirow{2}{*}{ Line } & \multicolumn{2}{|c|}{ Case 1} & \multicolumn{2}{|c|}{ Case 2} & \multicolumn{2}{|c|}{ Case 3 (HPSO) } & \multirow{2}{*}{$\begin{array}{r}\text { Line } \\
\text { Limit }\end{array}$} \\
\hline & Send & Rec. & Send & Rec. & Send & Rec. & \\
\hline $1-2$ & 0.1960 & 0.2392 & 0.1723 & 0.2234 & 0.1455 & 0.1489 & 1 \\
\hline $1-5$ & 0.5863 & 0.5671 & 0.3860 & 0.3790 & 0.4493 & 0.4385 & 0.6 \\
\hline $2-3$ & 0.9155 & 0.9054 & 0.7897 & 0.7796 & 0.9999 & 0.9898 & 1 \\
\hline $2-4$ & 0.8385 & 0.8089 & 0.5766 & 0.5602 & 0.9668 & 0.9391 & 1 \\
\hline $2-5$ & 0.6938 & 0.6734 & 0.4897 & 0.4774 & 0.5149 & 0.5001 & 0.6 \\
\hline $3-4$ & 0.2171 & 0.2408 & 0.3020 & 0.3184 & 0.1551 & 0.1820 & 1.2 \\
\hline $4-5$ & 0.6366 & 0.6419 & 0.3970 & 0.3990 & 0.3990 & 0.4000 & 0.4 \\
\hline $10-11$ & 0.1395 & 0.1228 & 0.1357 & 0.1031 & 0.1855 & 0.1823 & 1 \\
\hline $12-13$ & 0.0401 & 0.0761 & 0.0294 & 0.0786 & 0.0498 & 0.0764 & 1.5 \\
\hline $13-14$ & 0.1327 & 0.1432 & 0.0939 & 0.1250 & 0.1756 & 0.1746 & 0.4 \\
\hline $6-11$ & 0.1755 & 0.1917 & 0.1071 & 0.1584 & 0.2483 & 0.2480 & 1.2 \\
\hline $6-12$ & 0.1584 & 0.1464 & 0.1469 & 0.1383 & 0.1682 & 0.1545 & 1 \\
\hline $6-13$ & 0.3385 & 0.3337 & 0.2989 & 0.2985 & 0.3750 & 0.3672 & 0.8 \\
\hline $9-10$ & 0.0752 & 0.0506 & 0.1658 & 0.1343 & 0.0307 & 0.0532 & 1 \\
\hline $9-14$ & 0.1417 & 0.1347 & 0.1989 & 0.1818 & 0.0945 & 0.1025 & 1.2 \\
\hline $7-8$ & 0.2109 & 0.2000 & 0.9573 & 0.9510 & 0.2187 & 0.2082 & 1.2 \\
\hline $7-9$ & 0.5025 & 0.5082 & 0.7525 & 0.7518 & 0.4431 & 0.4535 & 0.8 \\
\hline $4-7$ & 0.2916 & 0.2936 & 0.2375 & 0.2513 & 0.2174 & 0.2242 & 1 \\
\hline $4-9$ & 0.2096 & 0.2175 & 0.0869 & 0.1250 & 0.1680 & 0.1844 & 0.5 \\
\hline $5-6$ & 0.4672 & 0.4660 & 0.3270 & 0.3204 & 0.4331 & 0.4296 & 0.5 \\
\hline
\end{tabular}

Table 8: Parameters of UPFC in IEEE-14 bus system

\begin{tabular}{ccccc}
\hline $\begin{array}{c}\text { Control } \\
\text { Parameters of } \\
\text { UPFC }\end{array}$ & \multicolumn{2}{c}{ Series source } & \multicolumn{2}{c}{ Shunt source } \\
$\mathrm{V}_{\mathrm{cR}}$ & $\theta_{\mathrm{cR}}(\mathrm{deg})$ & $\begin{array}{c}\mathrm{V}_{\mathrm{vR}} \\
(\mathrm{pu})\end{array}$ & $\theta_{\mathrm{vR}}(\mathrm{deg})$ \\
\hline GA & -0.0736 & -36.7565 & 0.9540 & -5.3705 \\
PSO & 0.0366 & -60.3009 & 0.9820 & -10.7465 \\
HPSO & 0.0386 & -59.5471 & 0.9862 & -10.8628 \\
\hline
\end{tabular}

\section{CONCLUSION}

This paper presents the application of HPSO technique to find the optimal location of UPFCs for getting minimum total active and reactive power production cost of generators and to minimize the installation cost of UPFCs.

The UPFC can provide control of voltage magnitude, voltage phase angle and impedance. Therefore, it can be utilized to effectively increase power transfer capability of the existing power transmission lines, and reduce operational and investment costs. It offers a mechanism that may help traditional congestion mitigation methods and in some cases may prevent generators to run in out-of-merit order, and may prevent load shedding or curtailment that would be required to maintain system security.

Simulations were performed on four-bus test system and IEEE-14 bus system. Optimizations were performed on the control parameters including the location of the UPFCs and their settings in the line. Results show that utilizing UPFC may reduce generation costs. PSO technique gives minimum cost of power production and installation of UPFC when compared with genetic algorithm that derived of swarm behavior in the PSO algorithm. The HPSO algorithm was basically the standard PSO combined with genetic operators. The optimal solutions found by the HPSO were better than those found by the standard PSO method. It is also noted that the convergence speed is faster in HPSO method.

\section{REFERENCES}

1. Bésanger Y., Passelergue J.C., Hadj-Said N., Feuillet R., 1996. Improvement of power system performance by inserting FACTS devices, In Proc. IEE AC and DC Power Transmission Conf., London, UK: 263-268.

2. Squires R.B., 1961. Economic Dispatch of Generation Directly from Power System Voltage and Admittances, IEEE Trans. on PAS-79 (3): 1235-1244.

3. Gerbex S., Cherkaoui R., Germond A.J., 2001. Optimal Location of Multi-type FACTS devices by Means of Genetic Algorithm, IEEE Trans. PWRS, Vol. 16: 537- 544.

4. Ma, T.T., 2003. Enhancement of Power Transmission systems by using multiple UPFC on Evolutionary Programming, IEEE Bologna Power Tech Conference, Vol. 4.

5. Venkatesh P., Gnanadass R., Padhy N.P., 2003. Comparison and Application of Evolutionary Programming Techniques to Combined Economic Emission Dispatch with Line Flow Constraints, IEEE Trans. PWRS, Vol. 18: 688-697.

6. Kennedy J., Eberhart R., 1995. Particle Swarm Optimization, Proc. of IEEE Int. Conf. on Neural Network, Vol. 4: 1942-1948.

7. Shi Y., Eberhart R.C., 1999. Empirical Study of PSO, Proc. of the Congress on Evolutionary Computation, Vol. 3: 1945- 1950.

8. Kannan S., Slochanal S.M.R., Subbaraj P., Pandhay N.P., 2004. Application of PSO Technique and its Variants to Generation Expansion Planning problem, Int. J. on Electric Power Systems Research, Vol. 70: 203-210. 
9. Angeline P., 1998. Evolutionary Optimization versus PSO Philosophy and Performance differences, In Proc. 7th Ann. Conf. Evolutionary Program: 601-610.

10. Løvbjerg M., Rasmussen T., Krink T., 2001. Hybrid PSO with Breeding and Subpopulations, Proceedings of the third Genetic and Evolutionary Computation Conference (GECCO-2001), Vol. 1: 469-476.

11. Parerni P., Vitet S., Bena M., Yokoyama A., 1999. Optimal Location of Phase Shifters in the French Network by Genetic Algorithm, IEEE Trans. PWRS, Vol. 14, No. 1: 37-42.

12. Singh, S.N., David A.K., 2001. A New Approach for Placement of FACTS devices in Open Power Markets, IEEE Power Eng. Rev., Vol. 21, No. 9: 58-60.

13. Bhasaputra P., Ongsaku W.L, 2002. Optimal Power Flow with Multi-type of FACTS Devices by Hybrid TS/SA Approach, IEEE Proc. on International Conference on Industrial Technology, Vol. 1: 285- 290.

14. Saravanan M., Slochana S.M.R.L, Venkatesh P., Abraham P.S., 2005. Application of PSO Technique for Optimal Location of FACTS devices Considering System Loadability and Cost of Installation, IEEE Power Engineering Conference, 29 Nov.-2 Dec., No 1: 716- 721.

15. Gyugyi L., Schauder C.D., Williams S.L., Reitman T.R., Torgerson D. R., Edris A., 1995. The UPFC: a New Approach to Power Transmission Control, IEEE Trans. PWRD, Vol. 10, No. 2: 1085-1097.

16. Gyugyi L., et al., 1998. Operation of the Unified Power Flow Controller under Practical Constraints, IEEE Trans. PWRD, Vol. 13, No. 2: 630-639.

17. Fuerte-Esquivel C.R., Acha E., 1997. Unified Power Flow Controller: a Critical Comparison of Newton-Raphson UPFC Algorithms in Power Flow Studies, IEE Proc.-C, Vol. 144, No. 5: 437-444.
18. Miranda V., Fonseca N., 2002. New Evolutionary Particle Swarm Algorithm (EPSO) Applied to Voltage/VAR Control, The 14th PSCC Conference (PSCC'02-2002), Seville, Spain.

19. Blackwell T., Bentley P.J., 2002. Don't push me! collision-avoiding swarms, IEEE Congress on Evolutionary Computation, Honolulu, Hawaii USA.

20. Krink T., Vesterstrøm J. S., Riget J., 2002. PSO with Spatial Particle Extension, Proceedings of the Fourth Congress on Evolutionary Computation (CEC-2002).

21. Ratnaweera A., Halgamuge S.K., Watson H.C., 2004. Self-Organizing Hierarchical PSO Optimizer with Time Varying Accelerating Coefficients, IEEE 2004 Trans. on Evolutionary Computation (accepted for special issue on PSO).

22. Parsopoulos K.E., Vrahatis M.N., 2002. PSO Method for Constrained Optimization Problems, Proceedings of the Euro-International Symposium on Computational Intelligence (E-ISCI 2002).

23. Lamont J.W., Fu J., 1999. Cost Analysis of Reactive Power Support, IEEE Trans. PWRS, Vol. 14, No. 29: 890-898.

24. Alomoush M., 2003. Derivation of UPFC DC Load Flow Model With Examples of its Use Restructured Power Systems, IEEE Trans. PWRS, Vol. 18, No. 3: 1173-1180.

25. IEEE 14-Bus Test System Data [Online]. Avalable: http://www.ee.washington.edu/research/pstca/pf14/ pg tca14bus.htm. 